\title{
Nuclear Receptors, Metabolism, and the Circadian Clock
}

\author{
X. YANG, ${ }^{*}$ K.A. LAMIA, ${ }^{*}$ R.M. Evans \\ Gene Expression Laboratory, Howard Hughes Medical Institute, The Salk Institute \\ for Biological Studies, La Jolla, California 92037
}

\begin{abstract}
As ligand-dependent transcription factors, the nuclear receptor superfamily governs a remarkable array of rhythmic physiologic processes such as metabolism and reproduction. To provide a "molecular blueprint" for nuclear receptor function in circadian biology, we established a diurnal expression profile of all mouse nuclear receptors in critical metabolic tissues. Our finding of broad expression and tissue-specific oscillation of nuclear receptors along with their key target genes suggests that diurnal nuclear receptor expression may contribute to established rhythms in metabolic physiology and that nuclear receptors may be involved in coupling peripheral circadian clocks to divergent metabolic outputs. Conversely, nuclear receptors may serve peripheral clock input pathways, integrating signals from the light-sensing central clock in the suprachiasmatic nucleus and other environmental cues, such as nutrients and xenobiotics. Interplay between the core circadian clock and nuclear receptors may define a large-scale signaling network that links biological timing to metabolic physiology.
\end{abstract}

\section{INTRODUCTION}

The prototypes of the nuclear receptor (NR) superfamily were identified as the steroid receptors that mediate gene transcription in response to steroid hormone signaling (Evans 1988). To date, a total of 48 human NR genes have been identified, including classic endocrine receptors for steroid hormones, thyroid hormones, and Vitamin $\mathrm{A}$ and $\mathrm{D}$ derivatives, and a large number of orphan receptors whose ligands and physiological functions were initially unknown (Giguere et al. 1988; Mangelsdorf et al. 1995; Giguere 1999). The past decade has witnessed stunning advances in orphan receptor research, largely owing to the identification of dietary lipids and metabolites as the ligands for a number of orphan receptors and establishing these adopted orphan receptors as lipid sensors that activate transcriptional programs for metabolic homeostasis (Chawla et al. 2001). For approximately half of the NR superfamily members, no ligands have yet been identified. However, their diverse roles in development, reproduction, and general metabolism have begun to be uncovered.

Many aspects of mammalian physiology are robustly rhythmic. Among these rhythmic phenomena, reproductive physiology, glucose and lipid homeostasis, and toxin clearance broadly depend on hormones and metabolites that serve as ligands for NRs. For example, periodic variations in estrogen and progesterone levels drive female menstrual cycles, whereas a morning surge in cortisol boosts energy production. A large array of metabolites, such as glucose, free fatty acids, and cholesterol and bile acids, also exhibit daily fluctuation, which is thought to be controlled by the intrinsic circadian timing system and in turn may regulate metabolic rhythms through adopted orphan receptors (Back et al. 1969; Yang et al. 2006).

The mammalian circadian timing system comprises a central pacemaker in the suprachiasmatic nucleus $(\mathrm{SCN})$ of

\footnotetext{
* These authors contributed equally to this work
}

the hypothalamus and numerous peripheral tissue oscillators. The central clock is directly entrained by light from the retina via the retinohypothalamic tract, whereas the peripheral oscillators can be synchronized either by neuronal and hormonal signals from the central clock or by other environmental cues such as daily feeding/fasting or activity/rest cycles (Kohsaka and Bass 2007; Levi and Schibler 2007). This hierarchy of circadian clocks coordinates daily cycles of physiology and behavior, allowing animals to adapt to predictable changes in the environment, likely promoting fitness, health, and longevity of the organism.

In this chapter, we discuss molecular and functional links between nuclear receptors and circadian clocks, with emphasis on implications for metabolic physiology (Fig. 1).

\section{NRs WITHIN THE CORE CLOCKWORK}

Circadian clocks are self-sustained, cell-autonomous molecular oscillators. The current view of the clockwork is two interlocked transcriptional/posttranslational feedback loops comprising a battery of transcriptional activators and repressors (Hardin 2006; Ko and Takahashi 2006). A heterodimeric complex of BMAL1 and either CLOCK or NPAS2 activate the transcription of Period genes (Per1, Per2, and Per3) and Cryptochrome genes (Cryl and Cry2) by recognizing E-box cis-regulatory elements in their promoters. Upon accumulating to a critical concentration, PER and CRY move to the nucleus and inhibit the transcription of their own genes by blocking BMAL1-CLOCK/NPAS2 activity. Clock expression is generally constant, whereas rhythmic transcription of Bmall is driven by a second feedback loop, involving the orphan nuclear receptors ROR $\alpha$ and REV-ERB $\alpha$ (Preitner et al. 2002; Sato et al. 2004).

The ROR $(\alpha, \beta, \gamma)$ and REV-ERB $(\alpha$ and $\beta)$ proteins represent closely related families of NRs that recognize similar cis response elements (ROREs) on target genes (Forman et al. 1994). RORs act as constitutive transcriptional activators, whereas REV-ERBs are constitutive 


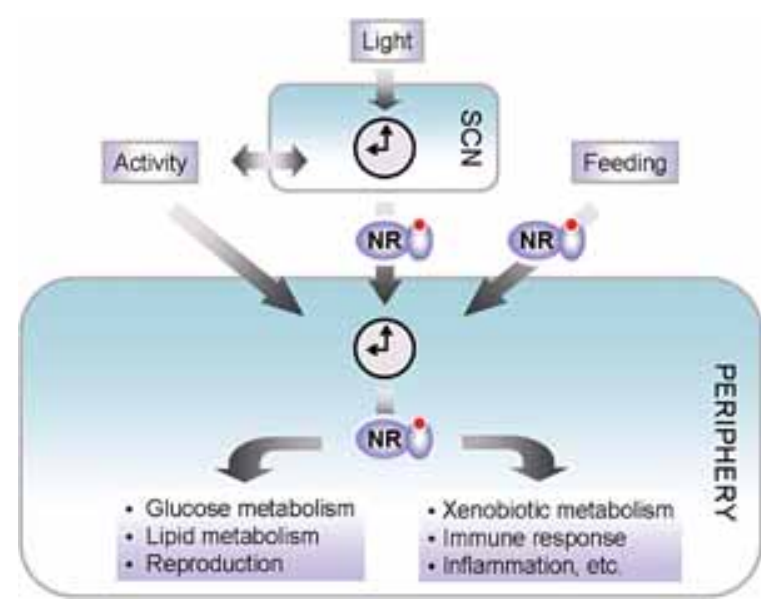

Figure 1. Potential roles of nuclear receptors in the circadian timing system. The central clock in the suprachiasmatic nucleus $(\mathrm{SCN})$ is directly entrained by light to the solar time. The clocks in peripheral tissues can be synchronized either by neuronal and hormonal signals from the central clock or by other environmental cues such as daily feeding and activity cycles. NRs may function in multiple layers of this circadian clock hierarchy. Some NRs such as ROR $\alpha$ and REV-ERB $\alpha$ are components of the core clockwork. By sensing fat-soluble hormones, vitamins, and dietary lipids in the circulation, NRs may transmit circadian signals from the central clock and/or the feeding cycle into the peripheral clocks. NRs may also act as circadian output factors to drive rhythmic physiologic processes including metabolism, immune response, and reproduction.

repressors. As a result, $\mathrm{ROR} \alpha$ and $\mathrm{REV}-\mathrm{ERB} \beta$ regulate Bmall transcription in an opposing manner by competitively binding to ROREs in its promoter (Preitner et al. 2002; Sato et al. 2004; Akashi and Takumi 2005). Alternate action of these two NRs over each light/dark cycle leads to rhythmic expression of Bmall. Closing the feedback loop, BMAL1-CLOCK directly regulates the transcription of Rev-erb $\alpha$ via E-box elements in its promoter (Preitner et al. 2002). The promoter of the Rev$e r b \alpha$ gene also contains a functional RORE through which it is repressed by itself and induced by ROR $\alpha$ (Delerive et al. 2002; Raspe et al. 2002). This additional layer of regulation may ensure antiphase expression of $R O R \alpha$ and Rev-erb $\alpha$, thus enhancing the precision, robustness, or sustainability of the clock.

The functions of closely related REV-ERB $\beta, \operatorname{ROR} \beta$, and ROR $\gamma$ isoforms are not well understood. We found that expression of Rev-erb $\beta$ mRNA is similar to that of Reverb $\alpha$ in both tissue distribution and temporal profile (Yang et al. 2006). Although REV-ERB $\alpha$ has been more intensively studied with regard to circadian rhythms and the mechanisms by which it can repress Bmall transcription have been described in some molecular detail (Yin and Lazar 2005), it has been reported that REV-ERB $\beta$ is capable of repressing Bmall transcription with a strength similar to that of REV-ERB $\alpha$ (Guillaumond et al. 2005). Thus, REV-ERB $\beta$ may contribute to Bmall expression in a manner similar and partially redundant to REVERB $\alpha$. Mice with a null mutation of the Rev-erb $\alpha$ locus were found to have a slightly shorter free-running period in constant dark- ness (DD) and increased phase shifts in response to light pulses compared to wild-type controls (Preitner et al. 2002). Perhaps mice lacking both Rev-erb $\alpha$ and Rev-erb $\beta$ function would display a stronger disruption of circadian function. Further studies on Rev-erb $\alpha$ - and Rev-erb $\beta$-deficient mouse models would illuminate the separate and distinct roles of the REV-ERB family members in the functioning of the circadian oscillator.

In contrast to the uniform diurnal expression patterns of Rev-erb $\alpha$ and Rev-erb $\beta$ across tissues, Ror $\alpha, \beta$, and $\gamma$ isoforms exhibit diverse temporal and spatial expression patterns (Akashi and Takumi 2005; Guillaumond et al. 2005; Bookout et al. 2006; Yang et al. 2006). Although widely expressed, Ror $\alpha$ transcripts robustly cycle in the SCN but are seemingly arrhythmic or display low-amplitude diurnal rhythms of expression in the four peripheral tissues that we examined (Ueda et al. 2002; Yang et al. 2006). Staggerer mice, which lack functional $\operatorname{ROR} \alpha$, have a decreased period of free-running locomotor activity in DD and slightly reduced Bmall expression in the SCN (Sato et al. 2004; Akashi and Takumi 2005). The expression of other core clock genes is unaffected. This modest phenotype may be due to partial compensation by ROR $\beta$, which is also highly expressed in the SCN with a circadian rhythm of expression similar to that of the Period gene transcripts (Sumi et al. 2002). Genetic disruption of $\operatorname{Ror} \beta$ increases the free-running period in mice (Andre et al. 1998; Masana et al. 2007). Ror $\gamma$ mRNA is highly expressed in the periphery and cycles in selective tissues (Yang et al. 2006). Mice lacking functional ROR $\gamma$ have not been described.

The nuclear receptor coactivator PGC1 $\alpha$, which was originally cloned as a cofactor of the PPAR family of NRs and has been shown to bind and regulate the activity of multiple NRs (Puigserver et al. 1998; Knutti et al. 2000), was recently shown to coactivate ROR $\alpha$ and ROR $\gamma$ on the Bmall promoter RORE (Liu et al. 2007). PGC1 $\alpha^{-/-}$mice seem to have a slightly increased free-running period in $\mathrm{DD}$, although it is unclear whether this result is statistically significant (Liu et al. 2007). In contrast, ROR $\alpha$ mutant Staggerer mice have a slightly decreased free-running period of locomotor activity, suggesting that a mild effect of PGC1 $\alpha$ loss on free-running period would not be due primarily to loss of coactivation of ROR $\alpha$ but may result from the loss of coactivation of ROR $\beta, \operatorname{ROR} \gamma$, or other NRs. PGC1 $\beta^{-/-}$mice exhibit decreased nocturnal locomotor activity under light/dark conditions, which may be due to a disturbance of the circadian system (Sonoda et al. 2006).

An earlier report suggested a role for the nuclear receptor Ear2 (also known as COUP-TFIII) in the maintenance of circadian rhythmicity because Ear $2^{-/}$mice were found to have increased error in the timing of locomotor activity onsets and their behavioral rhythms degraded in response to lower intensities of constant light (LL) compared to wild-type controls (Warnecke et al. 2005). However, the same animals exhibited distorted architecture of several neuronal structures, raising the concern that their disrupted circadian behaviors may be due to developmental defects rather than to disruption of the circadian clock in adult animals. Conditional deletion of Ear2/COUP-TFIII 
in adult neurons would resolve this question. In our study, transcripts encoding all three members of the COUP-TF family of NRs were expressed arrhythmically in all tissues examined (Yang et al. 2006).

Transcripts encoding the highly related nuclear receptors NGFI-B, NOR1 and NURR1 (also known as NR4A1, NR4A2, and NR4A3) displayed striking high-amplitude diurnal patterns of expression in most tissues examined in our study. The Ngfi-b transcript was also reported to be strongly induced by light in the hamster SCN (Morris et al. 1998), which led to the hypothesis that NGFI-B may have a role in either light entrainment or maintenance of circadian rhythmicity. However, $\mathrm{Ng} f \mathrm{i}-\mathrm{b}^{-/-}$mice did not exhibit any disruption of circadian locomotor behavior under constant conditions and displayed normal behavioral phase shifting in response to a variety of light stimuli (Kilduff et al. 1998). Because there are three highly homologous receptors in the NR4A family and they have similar diurnal rhythms of expression, they are likely redundant for some functions, possibly including circadian clock entrainment. The function of the ubiquitous, strongly diurnal expression of the NR4A receptors remains unexplained.

\section{NRS MAY MEDIATE ENTRAINMENT OF PERIPHERAL CLOCKS BY METABOLIC SIGNALS}

Elegant experiments within the last decade established that fasting and feeding patterns are the primary determinant of the timing of peripheral circadian clocks (Damiola et al. 2000; Stokkan et al. 2001). However, the mechanisms by which feeding time sets peripheral clocks remain obscure and may include both neural and humoral components. Circulating factors that are involved in the entrainment of peripheral clocks by feeding time would be expected to display robust diurnal rhythms in the circulation that are altered by changing the time of restricted feeding. Many NR ligands meet these criteria, including glucocorticoids, triiodothyronine (T3), thyroxine (T4), retinoic acid, and dietary lipids. One or many of such molecules may determine the timing of all peripheral clocks; alternatively, unique factors or combinations of factors, possibly including one or more NR ligands, may entrain various peripheral organ clocks.

\section{Glucocorticoids}

Circulating glucocorticoids display strong diurnal rhythms, and glucocorticoids have been shown to induce the expression of circadian transcripts in cultured cells (Balsalobre et al. 2000a,b), which made these steroid hormones attractive candidates for peripheral entrainment cues. However, recent evidence argues against their role as a major time cue for peripheral clocks (Le Minh et al. 2001). Similar detailed analysis of the potential for other NR ligands to entrain peripheral circadian clocks has not yet been done and would be required to make conclusions about their physiological roles in peripheral clock entrainment.

\section{Thyroid Hormones}

Thyroid stimulating hormone (TSH), T3, and T4 are robustly rhythmic in the circulation in rodents, and the circadian rhythm of TSH has been shown to be driven by circadian clock function in human subjects (Allan and Czeisler 1994). Furthermore, the phases of T3 and T4 rhythms are completely reversed by reversed-phase restricted feeding (Ahima et al. 1998). Finally, thyroidectomy alters the diurnal expression of clock genes outside of the SCN (Amir and Robinson 2006).

\section{Retinoic Acid}

Retinoic acid is the ligand for heterodimeric NR complexes containing RAR and RXR. RAR and RXR associate with CLOCK and NPAS2 (also known as MOP4) in a hormone-dependent fashion (McNamara et al. 2001). The same study also found that retinoic acid could inhibit CLOCK-mediated transcription both in cultured muscle cells and in cardiovascular organs from intact animals. Moderate phase shifts of peripheral clocks in the heart and aorta were observed after injection of retinoic acid. An independent screen tested 299 peptides and bioactive lipids for the ability to mediate entrainment of circadian rhythms in cultured fibroblasts expressing Per2luciferase. Of the 12 targets active in their screen, 3 were all trans-retinoic acid, 9-cis retinoic acid, and 13-cis retinoic acid (Nakahata et al. 2006). Moreover, there is evidence that retinoic acid signaling might be involved in light sensing and the central clock resetting (Thompson et al. 2004; Fu et al. 2005).

\section{PPAR Ligands}

The intestinal synthesis and degradation of oleylethanolamide (OEA) occur diurnally and are regulated by food intake (Fu et al. 2003, 2007). OEA is an endogenous ligand for PPAR $\alpha$ and inhibits appetite via PPAR $\alpha$ activation (Fu et al. 2003), presumably at hypothalamic sites. The timing and regulation of OEA synthesis and degradation are consistent with a potential role in the entrainment of peripheral circadian clocks. PPAR $\alpha$ regulates the transcription of both Bmall and Rev-erb $\alpha$ via PPRE cis-regulatory elements in their promoters (Canaple et al. 2006), suggesting a potential mechanism of contribution to peripheral clock entrainment. In addition, the endogenous PPAR $\gamma$ ligand 15-deoxy-Delta12,14-prostaglandin J2 was another of the 12 candidates found to entrain circadian rhythms in cultured fibroblasts by real-time monitoring of Per2-luciferase rhythms, further emphasizing the potential of dietary responsive NRs to influence the clock (Nakahata et al. 2006).

\section{Non-NR Ligands}

It is also possible that NRs participate in the entrainment of peripheral clocks in response to nutrient-derived signals that are not direct NR ligands such as glucose and insulin. Degradation of REV-ERB $\alpha$ protein is blocked by GSK3mediated phosphorylation (Yin et al. 2006). Because 
GSK3 activity is inhibited in response to acute bouts of feeding by insulin-stimulated AKT-mediated phosphorylation, degradation of REV-ERB $\alpha$ in response to feeding may contribute to the entrainment of peripheral clocks.

\section{NRs AS CIRCADIAN EFFECTORS OF METABOLISM}

Our survey of the diurnal expression profile of all 49 mouse nuclear receptors reveals wide expression and tissue-specific oscillation of NRs in a variety of metabolic tissues (Yang et al. 2006). From this analysis, we are not able to determine which cycling NR transcripts are driven directly by peripheral circadian clocks and which are responsive to physiological rhythms or to secondary clock-driven transcription factors. Nor did we measure NR protein levels and are thus unable to say which NRs are rhythmic at the protein level. However, there is evidence that several NR transcripts are directly regulated by CLOCK/BMAL1, and a few NR protein rhythms have been described that closely follow the rhythmic expression of the corresponding transcripts. The dynamic and coordinated changes in NR expression along with expression of their key target genes suggest that NRs may contribute to the regulation of divergent metabolic readouts by peripheral circadian clocks.

The NR transcripts most likely to be directly regulated by peripheral circadian clocks are those with peak expression at ZT 4 or ZT 8 in peripheral metabolic tissues, when CLOCK/BMAL1 heterodimers are most active in those tissues. The rhythmic expression of NR transcripts that oscillate in a tissue-specific manner may be driven by CLOCK-BMAL1 but may require additional cofactors that are expressed in a tissue-specific manner. We discuss a few examples of NRs that appear most likely to be directly controlled by peripheral circadian clocks and that would be expected to have a large impact on metabolic physiology, thus potentially linking peripheral circadian clocks to physiological rhythms.

\section{PPARs}

The roles of the PPAR family of transcription factors in various aspects of mammalian metabolic physiology are well established (Lee et al. 2003; Evans et al. 2004). Although the amplitudes of their diurnal expression patterns in some of the tissues that we examined are low, the rhythmicity of at least PPAR $\alpha$ is likely to be physiologically relevant. Both the PPAR $\alpha$ transcript and protein oscillate in mouse liver with a time of peak expression consistent with regulation by local circadian clocks (Lemberger et al. 1996). Ppar $\alpha$ transcription can be directly regulated by CLOCK and BMAL1 in vitro and in the liver and intestine in vivo (Inoue et al. 2005; Oishi et al. 2005; Canaple et al. 2006). As discussed above, the endogenous PPAR $\alpha$ ligand OEA is synthesized diurnally in the gut epithelium, probably in response to nutrient availability. Perhaps the rhythmic expression of PPAR $\alpha$ in the liver synergizes with OEA production to increase the amplitude of PPAR $\alpha$ activity on its target promoters. This mechanism may also have a role in the diurnal regulation of appetite, as OEA activation of PPAR $\alpha$ in the central nervous system (CNS) is a satiety signal. We did not measure the transcription of NRs in the CNS, so it is not clear whether a similar amplification of the signal is likely there.

\section{CAR}

The so-called constitutive androstane receptor (CAR) would be an interesting candidate for circadian regulation as it is a potent modulator of xenobiotic metabolism (Qatanani and Moore 2005). A recent elegant study showed that transcription of $C A R$ is regulated by the PARbZIP family of transcription factors, including DBP, HLF, and TEF, which in turn are regulated by CLOCK:BMAL1-dependent transcription and indeed are among the transcripts with the highest amplitude of circadian transcription in many organs (Gachon et al. 2006). In control animals, CAR expression peaks in the early night (ZT 12), whereas compound null mutations of Dbp, Hlf, and Tef result in loss of diurnal expression of CAR and its target genes, including many cytochrome family enzymes involved in the clearance of exogenous compounds by the liver. Physiologically, $\mathrm{Dbp}^{-/-}$; $\mathrm{Tef}^{--}$; $\mathrm{Hlf}^{/-}$animals have increased liver weight and reduced tolerance for anesthetic and chemotherapeutic agents. The combined diurnal expression of CAR with peak expression during the night phase when mice are actively ingesting food and diurnal sensitivity to exogenous agents that are both lost upon loss of the PARbZIP transcription factors suggests that these proteins have a critical role in optimizing circadian timing of toxin clearance to the phase of food ingestion.

\section{SHP}

We found that the Shp (small heterodimeric partner) transcript is robustly rhythmic in the liver but is not detectably expressed in adipose tissues or skeletal muscle (Yang et al. 2006). The SHP promoter contains E boxes and can be directly activated by CLOCK and BMAL1 (Oiwa et al. 2007). Furthermore, the ability of CLOCK and BMAL1 to drive transcription from the Shp promoter was found to be increased more than fivefold by coexpression of the nuclear receptor LRH-1 (Oiwa et al. 2007), which we found to be highly expressed in the liver compared to the other tissues examined, probably accounting for the tissuespecific oscillation of Shp transcription that we observed.

SHP is an orphan nuclear receptor that dimerizes with other NRs, including LXRs, FXR, and PXR, and represses their activities. Multiple NR partners of SHP have been shown to regulate the transcription of Cyp $7 a 1$ and Cyp8b2, among other transcripts involved in metabolizing dietary lipids and exogenous toxins (Schoonjans and Auwerx 2002). The loss of SHP function alone is sufficient to significantly increase the expression of $C y p 7 a 1$ and Cyp $8 b 2$ in the liver. Furthermore, when $S h p^{-/-}$mice are fed a diet high in cholesterol and/or cholic acid, their expression of detoxifying enzymes is strikingly higher than in control animals under similar conditions and they avoid the hepatic steatosis suffered by control animals (Wang et al. 2003). Taken together, these results imply that the liver-specific rhythmic expression of Shp is prob- 
ably driven by local circadian clocks and is expected to drive rhythmic repression of multiple NRs, thus contributing to daily rhythms in clearance of excess dietary lipids and other toxins.

\section{COMPLEXITY AND SPECIFICITY OF CIRCADIAN REGULATION BY NRs}

In metabolic pathways, certain circadian responsive target genes can be subject to direct regulation by multiple NRs and other factors. For example, evidence suggests that the Cyp7al gene is regulated by at least six NRs: LXR $\alpha$, LRH-1, FXR $\alpha$, PXR, RXR $\alpha$, and SHP (Chawla et al. 2000; Schoonjans and Auwerx 2002). Conversely, individual NRs participate in gene regulation in diverse cellular pathways. For example, PPAR $\gamma$ in adipocytes regulates genes involved in lipogenesis and lipid storage, glucose uptake, energy expenditure, and adipokine production (Lee et al. 2003; Evans et al. 2004). Furthermore, crosstalk within the NR superfamily has been widely documented. In the liver, the $S h p$ gene can be regulated by FXR $\alpha$, LRH-1, and ERR $\gamma$ (Lu et al. 2000; Sanyal et al. 2002), whereas the Rev-erb $\alpha$ gene can be regulated by ROR $\alpha$, PPAR $\alpha$, PPAR $\gamma$, and LXR (Gervois et al. 1999; Raspe et al. 2002; Fontaine et al. 2003). These NRs also interact functionally with other classes of transcriptional regulators such as SREBP-1c (Repa et al. 2000; Chen et al. 2004). Taken together, we propose that a large pool of NRs in any given peripheral tissue comprises an interlaced transcriptional network that coordinates multiple metabolic pathways in response to circadian and other cues.

In this complex regulatory network, how does the oscillation of an array of NRs give rise to specific rhythmic outputs? Several mechanisms could be involved. First, as suggested by our results and others (Panda et al. 2002), NRs appear to preferentially target rate-limiting genes in a metabolic pathway for circadian regulation. Second, for a battery of NRs that target a single gene, cycling of a minimal number of nuclear receptors seems to be sufficient to boost the oscillation of the target gene. This notion is supported by our observation that, among six nuclear receptors that are known to regulate $C y p 7 a 1$, only SHP is rhythmically expressed and appears to be the primary contributor to Cyp $7 a 1$ cycling. Third, for NRs that act as heterodimers, cyclic expression of one subunit may be sufficient for periodic changes in the heterodimer activity. Because RXRs serve as the partners for many other NRs (Mangelsdorf and Evans 1995), any dramatic changes in their levels would be detrimental. Indeed, we found that all RXR subtypes are continually expressed at fairly constant levels. In the absence of the cyclical induction of an RXR ligand, this places the critical regulation on the partner and/or its partner ligand; here, the PPARs may be one example.

\section{MULTIPLE LOOPS BETWEEN NRS AND THE CORE CLOCK}

In the above sections, we have depicted a scheme in which various NRs may be involved in circadian input and output pathways, as well as in the core clock mecha- nism. Feedback regulation is implicated at many points in circadian signal transduction. Not only does the core clock involve double interlocked feedback loops (Glossop et al. 1999; Shearman et al. 2000), but this type of feedback may also regulate communication between the core clockwork and input/output pathways. For example, PPAR $\alpha$ has been proposed to serve the input pathway by promoting Bmall and Rev-erb $\alpha$ expression (Gervois et al. 1999; Canaple et al. 2006). Conversely, BMAL1 and CLOCK directly regulate Ppar $\alpha$ transcription (Inoue et al. 2005; Oishi et al. 2005; Canaple et al. 2006). Xenobiotic metabolism is an important output of the circadian clock and xenobiotic compounds may, in turn, act as NR ligands to alter core clock gene expression (Claudel et al. 2007). We postulate that NRs and the core clock components are integrated into multiple feedback loops, which constitute a large-scale signaling network.

The signaling network connecting NRs and circadian clocks may serve a number of functions. First, as the double loops in the core clock are likely vulnerable to stochastic perturbation, additional loops involving NRs may improve the precision and robustness of peripheral clocks' 24-hour oscillations. In addition, this NR-clock network may sense a broad range of external cues, such as light, diet, and stress, by hormonal mechanisms, and integrate multiple input signals. In addition, NRs in this network regulate a variety of outputs that may link the core clock to diverse molecular genetic programs, thus orchestrating metabolism and physiology over the light/dark cycle. Finally, nearly half of the NR superfamily, including members of the ROR, REV-ERB, COUPTF, NGFI-B, RAR, RXR, TR, GR, PPAR, and ERR subfamilies, are ubiquitously expressed in all tested tissues (Bookout et al. 2006); other NRs are expressed either constitutively or diurnally in a tissue-specific manner. By regulating tissue-specific transcriptional programs, those NRs may create local versions of the circadian network.

\section{CONCLUDING REMARKS}

During the last decade, remarkable progress has been made in uncovering the molecular basis of the core circadian clockwork. However, we are just beginning to understand its biological inputs and outputs at a level ranging from gene expression to physiology and metabolism. In this chapter, we discussed evidence suggesting that the NR superfamily might constitute critical signaling cascades involved in coupling the circadian clock to divergent physiological outputs as well as in the clock entrainment by various zeitgebers. We have proposed that a conserved large-scale circadian network may emerge from feedback regulation between the NR and core clock genes. However, the existence and architecture of such NR-clock signaling network have yet to be determined. Although rhythmic expression is prevalent in the NR superfamily, it remains unknown which NRs (if any) are involved in peripheral clock resetting, which are solely responsive to the ticking output of the clock and which can manifest a diurnal rhythm as a result of other oscillatory cues.

Efficacy of NR signaling depends on the availability of receptors as well as their ligands. Hormonal ligands are 
usually produced in specific tissues such as the thyroid and adrenal glands and are delivered to target tissues via the circulation, although some active ligands can be generated in local tissues. Important questions yet to be answered include how the circadian clock affects endocrine and locally produced autocrine ligands and how ligand cycling is correlated with receptor cycling in regulation of rhythmic physiological processes. Furthermore, it remains elusive whether feeding/fasting cycles give rise to cyclic accumulation of dietary lipids and metabolites in the body, which would serve as ligands to stimulate the activity of adopted orphan receptors in a diurnal manner, thereby inducing cyclic expression of their target genes.

Understanding the mechanisms by which cellautonomous clocks are in sync at the tissue, organ, and system levels is a major challenge in the field of circadian biology. A plausible model is that, by sensing light, the central clock dictates rhythmic activity of the endocrine system which in turn entrains whole-body physiology to the light/dark cycle. Conditions of restricted feeding may overcome such SCN-driven entrainment by directly altering some endocrine functions. Nuclear hormone receptors represent a family of candidates that may be involved in the synchronization mechanisms of individual organs. Overall, the NR signaling system and the circadian timing system appear to be integrated at many levels (see Fig. 1), and it will be interesting to further elucidate their connections as we move toward understanding circadian inputs and outputs in greater detail.

\section{ACKNOWLEDGMENTS}

This work was supported by Atlas Grant U19DK6243401 (R.M.E.) and a NRSA postdoctoral fellowship (X.Y.) from the National Institutes of Health, a Merck fellowship from the Life Sciences Research Foundation (K.A.L.), and a short-term fellowship from the European Molecular Biology Organization (X.Y.). R.M.E. is an Investigator of the Howard Hughes Medical Institute and the March of Dimes Chair in Molecular and Developmental Biology.

\section{REFERENCES}

Ahima R.S., Prabakaran D., and Flier J.S. 1998. Postnatal leptin surge and regulation of circadian rhythm of leptin by feeding. Implications for energy homeostasis and neuroendocrine function. J. Clin. Invest. 101: 1020.

Akashi M. and Takumi T. 2005. The orphan nuclear receptor RORalpha regulates circadian transcription of the mammalian core-clock Bmal1. Nat. Struct. Mol. Biol. 12: 441.

Allan J.S. and Czeisler C.A. 1994. Persistence of the circadian thyrotropin rhythm under constant conditions and after lightinduced shifts of circadian phase. J. Clin. Endocrinol. Metab. 79: 508 .

Amir S. and Robinson B. 2006. Thyroidectomy alters the daily pattern of expression of the clock protein, PER2, in the oval nucleus of the bed nucleus of the stria terminalis and central nucleus of the amygdala in rats. Neurosci. Lett. 407: 254.

Andre E., Conquet F., Steinmayr M., Stratton S.C., Porciatti V., and Becker-Andre M. 1998. Disruption of retinoid-related orphan receptor beta changes circadian behavior, causes retinal degeneration and leads to vacillans phenotype in mice. EMBO J. 17: 3867.
Back P., Hamprecht B., and Lynen F. 1969. Regulation of cholesterol biosynthesis in rat liver: Diurnal changes of activity and influence of bile acids. Arch. Biochem. Biophys. 133: 11.

Balsalobre A., Marcacci L., and Schibler U. 2000a. Multiple signaling pathways elicit circadian gene expression in cultured Rat-1 fibroblasts. Curr. Biol. 10: 1291.

Balsalobre A., Brown S.A., Marcacci L., Tronche F., Kellendonk C., Reichardt H.M., Schutz G., and Schibler U. $2000 \mathrm{~b}$. Resetting of circadian time in peripheral tissues by glucocorticoid signaling. Science 289: 2344.

Bookout A.L., Jeong Y., Downes M., Yu R.T., Evans R.M., and Mangelsdorf D.J. 2006. Anatomical profiling of nuclear receptor expression reveals a hierarchical transcriptional network. Cell, 126: 789.

Canaple L., Rambaud J., Dkhissi-Benyahya O., Rayet B., Tan N.S., Michalik L., Delaunay F., Wahli W., and Laudet V. 2006. Reciprocal regulation of brain and muscle Arnt-like protein 1 and peroxisome proliferator-activated receptor alpha defines a novel positive feedback loop in the rodent liver circadian clock. Mol. Endocrinol. 20: 1715.

Chawla A., Saez E., and Evans R.M. 2000. "Don't know much bile-ology." Cell 103: 1.

Chawla A., Repa J.J., Evans R.M., and Mangelsdorf D.J. 2001. Nuclear receptors and lipid physiology: opening the X-files. Science 294: 1866.

Chen G., Liang G., Ou J., Goldstein J.L., and Brown M.S. 2004. Central role for liver X receptor in insulin-mediated activation of Srebp-1c transcription and stimulation of fatty acid synthesis in liver. Proc. Natl. Acad. Sci. 101: 11245.

Claudel T., Cretenet G., Saumet A., and Gachon F. 2007. Crosstalk between xenobiotics metabolism and circadian clock. FEBS Lett. 581: 3626.

Damiola F., Le Minh N., Preitner N., Kornmann B., FleuryOlela F., and Schibler U. 2000. Restricted feeding uncouples circadian oscillators in peripheral tissues from the central pacemaker in the suprachiasmatic nucleus. Genes Dev. 14: 2950.

Delerive P., Chin W.W., and Suen C.S. 2002. Identification of Reverb(alpha) as a novel ROR(alpha) target gene. J. Biol. Chem. 277: 35013.

Evans R.M. 1988. The steroid and thyroid hormone receptor superfamily. Science 240: 889.

Evans R.M., Barish G.D., and Wang Y.X. 2004. PPARs and the complex journey to obesity. Nat. Med. 10: 355.

Fontaine C., Dubois G., Duguay Y., Helledie T., Vu-Dac N., Gervois P., Soncin F., Mandrup S., Fruchart J.C., FruchartNajib J., and Staels B. 2003. The orphan nuclear receptor Rev-Erbalpha is a peroxisome proliferator-activated receptor (PPAR) gamma target gene and promotes PPARgammainduced adipocyte differentiation. J. Biol. Chem. 278: 37672 .

Forman B.M., Chen J., Blumberg B., Kliewer S.A., Henshaw R., Ong E.S., and Evans R.M. 1994. Cross-talk among ROR alpha 1 and the Rev-erb family of orphan nuclear receptors. Mol. Endocrinol. 8: 1253.

Fu J., Astarita G., Gaetani S., Kim J., Cravatt B.F., Mackie K., and Piomelli D. 2007. Food intake regulates oleoylethanolamide formation and degradation in the proximal small intestine. J. Biol. Chem. 282: 1518.

Fu J., Gaetani S., Oveisi F., Lo Verme J., Serrano A., Rodriguez De Fonseca F., Rosengarth A., Luecke H., Di Giacomo B., Tarzia G., and Piomelli D. 2003. Oleylethanolamide regulates feeding and body weight through activation of the nuclear receptor PPAR-alpha. Nature 425: 90.

Fu Y., Zhong H., Wang M.H., Luo D.G., Liao H.W., Maeda H., Hattar S., Frishman L.J., and Yau K.W. 2005. Intrinsically photosensitive retinal ganglion cells detect light with a vitamin A-based photopigment, melanopsin. Proc. Natl. Acad. Sci. 102: 10339.

Gachon F., Olela F.F., Schaad O., Descombes P., and Schibler U. 2006. The circadian PAR-domain basic leucine zipper transcription factors DBP, TEF, and HLF modulate basal and inducible xenobiotic detoxification. Cell Metab. 4: 25. 
Gervois P., Chopin-Delannoy S., Fadel A., Dubois G., Kosykh V., Fruchart J.C., Najib J., Laudet V., and Staels B. 1999. Fibrates increase human REV-ERBalpha expression in liver via a novel peroxisome proliferator-activated receptor response element. Mol. Endocrinol. 13: 400.

Giguere V. 1999. Orphan nuclear receptors: From gene to function. Endocr. Rev. 20: 689.

Giguere V., Yang N., Segui P., and Evans R.M. 1988. Identification of a new class of steroid hormone receptors. Nature 331: 91.

Glossop N.R., Lyons L.C., and Hardin P.E. 1999. Interlocked feedback loops within the Drosophila circadian oscillator. Science 286: 766.

Guillaumond F., Dardente H., Giguere V., and Cermakian N. 2005. Differential control of Bmall circadian transcription by REV-ERB and ROR nuclear receptors. J. Biol. Rhythms 20: 391.

Hardin P.E. 2006. Essential and expendable features of the circadian timekeeping mechanism. Curr. Opin. Neurobiol. 16: 686.

Inoue I., Shinoda Y., Ikeda M., Hayashi K., Kanazawa K., Nomura M., Matsunaga T., Xu H., Kawai S., Awata T., Komoda T., and Katayama S. 2005. CLOCK/BMAL1 is involved in lipid metabolism via transactivation of the peroxisome proliferator-activated receptor (PPAR) response element. J. Atheroscler. Thromb. 12: 169

Kilduff T.S., Vugrinic C., Lee S.L., Milbrandt J.D., Mikkelsen J.D., O'Hara B.F., and Heller H.C. 1998. Characterization of the circadian system of NGFI-A and NGFI-A/NGFI-B deficient mice. J. Biol. Rhythms 13: 347.

Knutti D., Kaul A., and Kralli A. 2000. A tissue-specific coactivator of steroid receptors, identified in a functional genetic screen. Mol. Cell. Biol. 20: 2411

Ko C.H. and Takahashi J.S. 2006. Molecular components of the mammalian circadian clock. Hum. Mol. Genet. (spec. no. 2) 15: R271.

Kohsaka A. and Bass J. 2007. A sense of time: How molecular clocks organize metabolism. Trends Endocrinol. Metab. 18: 4

Lee C.H., Olson P., and Evans R.M. 2003. Minireview: Lipid metabolism, metabolic diseases, and peroxisome proliferatoractivated receptors. Endocrinology 144: 2201.

Lemberger T., Saladin R., Vazquez M., Assimacopoulos F., Staels B., Desvergne B., Wahli W., and Auwerx J. 1996. Expression of the peroxisome proliferator-activated receptor alpha gene is stimulated by stress and follows a diurnal rhythm. J. Biol. Chem. 271: 1764.

Le Minh N., Damiola F., Tronche F., Schutz G., and Schibler U. 2001. Glucocorticoid hormones inhibit food-induced phaseshifting of peripheral circadian oscillators. EMBO J. 20: 7128

Levi F. and Schibler U. 2007. Circadian rhythms: Mechanisms and therapeutic implications. Annu. Rev. Pharmacol. Toxicol. 47: 593.

Liu C., Li S., Liu T., Borjigin J., and Lin J.D. 2007. Transcriptional coactivator PGC-1alpha integrates the mammalian clock and energy metabolism. Nature 447: 477.

Lu T.T., Makishima M., Repa J.J., Schoonjans K., Kerr T.A., Auwerx J., and Mangelsdorf D.J. 2000. Molecular basis for feedback regulation of bile acid synthesis by nuclear receptors. Mol. Cell 6: 507.

Mangelsdorf D.J. and Evans R.M. 1995. The RXR heterodimers and orphan receptors. Cell 83: 841 .

Mangelsdorf D.J., Thummel C., Beato M., Herrlich P., Schutz G., Umesono K., Blumberg B., Kastner P., Mark M., Chambon P., and Evans R.M. 1995. The nuclear receptor superfamily: The second decade. Cell 83: 835 .

Masana M.I., Sumaya I.C., Becker-Andre M., and Dubocovich M.L. 2007. Behavioral characterization and modulation of circadian rhythms by light and melatonin in $\mathrm{C} 3 \mathrm{H} / \mathrm{HeN}$ mice homozygous for the RORbeta knockout. Am. J. Physiol. Regul. Integr. Comp. Physiol. 292: R2357.

McNamara P., Seo S.P., Rudic R.D., Sehgal A., Chakravarti D., and FitzGerald G.A. 2001. Regulation of CLOCK and MOP4 by nuclear hormone receptors in the vasculature: A humoral mechanism to reset a peripheral clock. Cell 105: 877 .

Morris M.E., Viswanathan N., Kuhlman S., Davis F.C., and
Weitz C.J. 1998. A screen for genes induced in the suprachiasmatic nucleus by light. Science 279: 1544

Nakahata Y., Akashi M., Trcka D., Yasuda A., and Takumi T. 2006. The in vitro real-time oscillation monitoring system identifies potential entrainment factors for circadian clocks. BMC Mol. Biol. 7: 5 .

Oishi K., Shirai H., and Ishida N. 2005. CLOCK is involved in the circadian transactivation of peroxisome-proliferator-activated receptor alpha (PPARalpha) in mice. Biochem. J. 386: 575.

Oiwa A., Kakizawa T., Miyamoto T., Yamashita K., Jiang W., Takeda T., Suzuki S., and Hashizume K. 2007. Synergistic regulation of the mouse orphan nuclear receptor SHP gene promoter by CLOCK-BMAL1 and LRH-1. Biochem. Biophys. Res. Commun. 353: 895

Panda S., Antoch M.P., Miller B.H., Su A.I., Schook A.B. Straume M., Schultz P.G., Kay S.A., Takahashi J.S., and Hogenesch J.B. 2002. Coordinated transcription of key pathways in the mouse by the circadian clock. Cell 109: 307.

Preitner N., Damiola F., Lopez-Molina L., Zakany J., Duboule D., Albrecht U., and Schibler U. 2002. The orphan nuclear receptor REV-ERBalpha controls circadian transcription within the positive limb of the mammalian circadian oscillator. Cell 110: 251 .

Puigserver P., Wu Z., Park C.W., Graves R., Wright M., and Spiegelman B.M. 1998. A cold-inducible coactivator of nuclear receptors linked to adaptive thermogenesis. Cell 92: 829 .

Qatanani M. and Moore D.D. 2005. CAR, the continuously advancing receptor, in drug metabolism and disease. Curr. Drug Metab. 6: 329.

Raspe E., Mautino G., Duval C., Fontaine C., Duez H., Barbier O., Monte D., Fruchart J., Fruchart J.C., and Staels B. 2002. Transcriptional regulation of human Rev-erbalpha gene expression by the orphan nuclear receptor retinoic acidrelated orphan receptor alpha. J. Biol. Chem. 277: 49275.

Repa J.J., Liang G., Ou J., Bashmakov Y., Lobaccaro J.M., Shimomura I., Shan B., Brown M.S., Goldstein J.L., and Mangelsdorf D.J. 2000. Regulation of mouse sterol regulatory element-binding protein-1c gene (SREBP-1c) by oxysterol receptors, LXRalpha and LXRbeta. Genes Dev. 14: 2819.

Sanyal S., Kim J.Y., Kim H.J., Takeda J., Lee Y.K., Moore D.D., and Choi H.S. 2002. Differential regulation of the orphan nuclear receptor small heterodimer partner (SHP) gene promoter by orphan nuclear receptor ERR isoforms. J. Biol. Chem. 277: 1739 .

Sato T.K., Panda S., Miraglia L.J., Reyes T.M., Rudic R.D. McNamara P., Naik K.A., FitzGerald G.A., Kay S.A., and Hogenesch J.B. 2004. A functional genomics strategy reveals Rora as a component of the mammalian circadian clock. Neuron 43: 527

Schoonjans K. and Auwerx J. 2002. A sharper image of SHP. Nat.Med. 8: 789 .

Shearman L.P., Sriram S., Weaver D.R., Maywood E.S., Chaves I., Zheng B., Kume K., Lee C.C., van der Horst G.T., Hastings M.H., and Reppert S.M. 2000. Interacting molecular loops in the mammalian circadian clock. Science 288: 1013.

Sonoda J. Mehl I.R., Chong L.-W., Nofsinger R.N., and Evans R.M. 2006. PGC1b controls mitochondrial metabolism to modulate circadian activity, adaptive thermogenesis, and hepatic steatosis. Proc. Natl. Acad. Sci. 104: 5223.

Stokkan K.A., Yamazaki S., Tei H., Sakaki Y., and Menaker M. 2001. Entrainment of the circadian clock in the liver by feeding. Science 291: 490

Sumi Y., Yagita K., Yamaguchi S., Ishida Y., Kuroda Y., and Okamura H. 2002. Rhythmic expression of ROR beta mRNA in the mice suprachiasmatic nucleus. Neurosci. Lett. 320: 13. Thompson C.L., Selby C.P., Van Gelder R.N., Blaner W.S., Lee J., Quadro L., Lai K., Gottesman M.E., and Sancar A. 2004. Effect of vitamin A depletion on nonvisual phototransduction pathways in cryptochromeless mice. J. Biol. Rhythms 19: 504.

Ueda H.R., Chen W., Adachi A., Wakamatsu H., Hayashi S., Takasugi T., Nagano M., Nakahama K., Suzuki Y., Sugano S., Iino M., Shigeyoshi Y., and Hashimoto S. 2002. A transcription factor response element for gene expression during circadian night. Nature 418: 534. 
Wang L., Han Y., Kim C.S., Lee Y.K., and Moore D.D. 2003. Resistance of SHP-null mice to bile acid-induced liver damage. J. Biol. Chem. 278: 44475.

Warnecke M., Oster H., Revelli J.P., Alvarez-Bolado G., and Eichele G. 2005. Abnormal development of the locus coeruleus in Ear2(Nr2f6)-deficient mice impairs the functionality of the forebrain clock and affects nociception. Genes Dev. 19: 614.

Yang X. Downes M., Yu R.T., Bookout A.L., He W., Straume M., Mangelsdorf D.J., and Evans R.M. 2006. Nuclear recep- tor expression links the circadian clock to metabolism. Cell 126: 801.

Yin L. and Lazar M.A. 2005. The orphan nuclear receptor Reverbalpha recruits the $\mathrm{N}-\mathrm{CoR} / \mathrm{histone}$ deacetylase 3 corepressor to regulate the circadian Bmall gene. Mol. Endocrinol. 19: 1452 .

Yin L., Wang J., Klein P.S., and Lazar M.A. 2006. Nuclear receptor Rev-erbalpha is a critical lithium-sensitive component of the circadian clock. Science 311: 1002. 


\section{$8_{\mathrm{CSH}}^{\infty} \mathrm{C}$ Cold Spring Harbor Symposia SYMPOSIA}

\section{Nuclear Receptors, Metabolism, and the Circadian Clock}

X. Yang, K. A. Lamia and R. M. Evans

Cold Spring Harb Symp Quant Biol 2007 72: 387-394

Access the most recent version at doi:10.1101/sqb.2007.72.058 $\begin{array}{ll}\text { References } & \begin{array}{l}\text { This article cites } 69 \text { articles, } 23 \text { of which can be accessed free at: } \\ \text { http://symposium.cshlp.org/content/72/387.full.html\#ref-list-1 }\end{array}\end{array}$

\section{License}

Email Alerting

Receive free email alerts when new articles cite this article - sign up in the box at the Service top right corner of the article or click here.

To subscribe to Cold Spring Harbor Symposia on Quantitative Biology go to: http://symposium.cshlp.org/subscriptions 